\title{
Shift in theories
}

Anthony Hallam

Drifting Continents and Colliding Paradigms: Perspectives on the Geoscience Revolution. By John A Stewart. Indiana University Press: 1990. Pp. 272. \$35.

IN RECENT years there has been a huge growth of interest and activity in what one might call the science of science. The more philosophical approach, associated particularly with the names of Popper and Lakatos, emphasizes the intellectual aspects of scientific research, with atten-

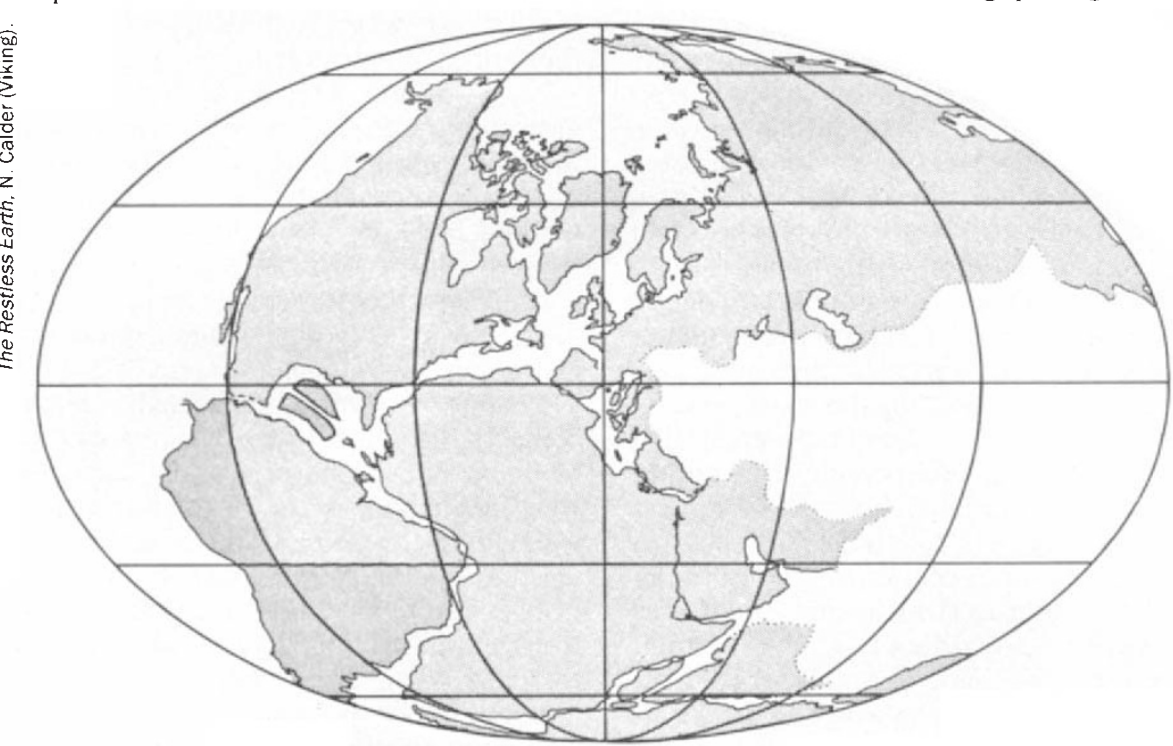

Pangaea - the continents fitted together along the edges of the present continental shelves.

tion being paid to logical analysis, rational deductions and the objective testing of hypothesis by observation or experiment. In contrast to this is the sociological approach initiated by Merton and Kuhn, in which attention is concentrated on the cultural traditions and social structure of the scientific community. Stress is laid on the crucial nature of decisions, such as what will be accepted by the consensus as valid evidence, and the inability of logical rules to specify how these decisions should be made. Among sociologists of science one can distinguish so-called functionalists, who attach greater importance to rational criteria, and constructivists, who focus attention more on the nature of the research process to see how norms and conventions become established. Greater emphasis is laid by the latter group on social factors such as scientists' reputations, style of presentation and institutional prestige. Both groups acknowledge the great importance of individual scientists' need for recognition, leading to much conflict and competition.

The geoscience revolution of the late 1960 s, leading to the general acceptance of plate tectonics, is one of the bestdocumented fields in the history of science, and offers promising material for the sociologist. More than half of Stewart's book is devoted to a recital of this history, effectively starting with Wegener's theory of continental drift and its generally adverse reception, and continuing in more detail with the new research in geophysics and oceanography that led to the revolution. This is all welltrodden ground, dealt with in numerous books of varying degrees of accessibility to the general public, but Stewart's account is balanced, thorough and well-illustrated, and indicates a good grasp of the subject for someone who is not a geoscientist by training. Full use is made of quotations from some of the leading protagonists,

to indicate how they evaluated the significance of what they were doing at the time. All well and good so far, except that I was not struck by any new insights.

In the more original part of the book, Stewart develops a model of the decisions needed to generate citation of a paper. He then uses this model to develop quantitative procedures for studying 'global' aspects of this decision process. The quantitative section is rather technical and probably of most interest to US sociologists, but the principal conclusion, which I find reassuring, is that papers are cited on cognitive rather than social grounds. The new paradigm of plate tectonics was accepted more rapidly by those with the most professional interest in it, namely geophysicists seeking some form of global theory. Others, such as structural geologists working in given regions of the continents, were less easily convinced, and subsequent 'negotiations' were required between the two groups, leading to a general acceptance of the need to allow, for example, internal deformation of plates and the existence of exotic terranes.

It is interesting to compare Stewart's book with the recently published volume on the same subject by Le Grand, with the very similar title of Drifting Continents and Shifting Theories (Cambridge University Press). Unlike Stewart, Le Grand is hostile to 'number-crunching' quantitative analysis, and follows Laudan rather than Kuhn in arguing that the fundamental aim of science is to maximize the scope and number of solved empirical and conceptual problems while minimizing the number of anomalies and conceptual problems generated. There is competition between rival research programmes and, within them, competition between theories. This greater emphasis on rational factors does not invalidate Stewart's more sociological approach but is in effect complementary to it. Stewart makes no extravagant claims for the statistical analysis he promotes, and is content to express the modest hope that it may point the way to more illumination in the future, in a variety of subject areas. $\mathrm{He}$ should find the current controversy about mass extinctions exceedingly promising material because of the wide variety of 'interest' groups involved, and the fact that nearly all the leading players are alive. Most important, perhaps, no consensus has yet been achieved on the cause of mass extinctions a decade after Alvarez put forward his impact hypothesis. This is in sharp contrast to the speed with which a consensus was reached on the essential correctness of plate tectonics.

One doesn't like to quibble, but it is embarrassing to see Merton's Matthew principle repeatedly referred to as the Matthews principle - Stewart is evidently unfamiliar with the New Testament. Although it is amusing to have a random scientist cited as she rather than he to provide a mild shock for male chauvinists, it is tedious to repeat this throughout the book, especially as Richard Dawkins made the point rather more deftly some years ago.

Anthony Hallam is Lapworth Professor of Geology, University of Birmingham, Birmingham B15 2TT, UK.

This year Nature's annual new journals review supplement will appear in the issue of 11 October. Publishers and iearned societies are invited to submit journals for review, taking note of the following criteria:

- Journals which first appeared after June 1988 , and which issued at least four separate numbers by the end of April 1990, will be considered for review. The deadline for submission is the end of June.

- Journals covering any aspect of science are eligible, although those dealing with clinical medicine, engineering and pure mathematics are excluded, as are publications of abstracts. - Frequency of publication must be at least three times a year.

- The main language used must be English.

When submitting journals for review, please send at least four different issues (the first, the most recent and any two others) of each title to: Book Review Editor, Nature, 4 Little Essex Street, London WC2R 3LF, UK. 